\title{
Evaluation of Risk Factors and Treatment of Peri-Partum Anemia
}

Safaa A. Ibrahim

Zagazig Universit

Mena M. Abdalla ( $\nabla$ dr.menasaleeb@yahoo.com )

Minya Health Insurance Hospital https://orcid.org/0000-0002-6395-0391

Rofida M. Elshafei

Stem Sharqia

Research Article

Keywords: Iron Deficiency Anemia, Blood Losses, Hemoglobin Level

Posted Date: February 22nd, 2021

DOI: https://doi.org/10.21203/rs.3.rs-236278/v1

License: (c) (i) This work is licensed under a Creative Commons Attribution 4.0 International License. Read Full License 


\section{Abstract}

Iron deficiency anemia (IDA) in pregnancy, i.e., prepartum anemia, is associated with premature birth, low birth weight, and small for gestational age of the newborn and is furthermore closely associated with the occurrence of anemia after delivery of a child, i.e., in the postpartum period .Post partum anemia is a common problem throughout the world. Through this study, aim of the work (frequency of post partum anemia and risk factors for its development) \& objectives was done. The study showed that percentage of antepartum anemia was about $64.3 \%$ this percentage postpartum increased to about $65.4 \%$ and $13.6 \%$ of those with antepartum normal hemoglobine level became anemic and there were $12.5 \%$ anemic improved postpartum and became normal. The major causes of postpartum anemia are prepartum iron deficiency/anemia in combination with excessive blood losses at delivery. Post partum anemia is not affected by demographic data, obstetric history, ante-partum u/s and partum history. Antepartum hemorrage was not significantly associated with postpartum anemia. The more the estimated blood loss during labor the more the postpartum anemia. Through follow up of post partum anemia cases and treated it according type of anemia (oral, intravenous, folate supplementation and blood transfusion) Outcome of treatment of anemia after 8 weeks $61.02 \%$ is improved \& $38.98 \%$ is not improved.

Conclusion: The major causes of postpartum anemia are prepartum iron deficiency/anemia in combination with excessive blood losses at delivery. The study showed that percentage of antepartum anemia was about $64.3 \%$ this percentage postpartum increased to about $65.4 \%$ and $13.6 \%$ of those with normal antepartum hemoglobine level became anemic postpartum and there were $12.5 \%$ anemic improved postpartum and became normal.

\section{Introduction}

An adequate iron status is essential for an uncomplicated course of pregnancy, a normal development of the fetus, and maturity of the newborn (1).

Iron deficiency anemia (IDA) in pregnancy, i.e., prepartum anemia, is associated with premature birth, low birth weight, and small for gestational age of the newborn and is furthermore closely associated with the occurrence of anemia after delivery of achild, i.e., in the postpartum period (1).

Postpartum iron deficiency and anemia are associated with an impaired quality of life from a physical and a psychological point of view and constitutes a significant health problem both in developed and developing countries (2)

Anemia after the delivery of a child (postpartum anemia) is a common problem throughout the world (3).

It has been estimated that of the $\sim 500,000$ maternal deaths occurring each year on a global scale in association with delivery, $20 \%$ are caused by peripartum hemorrhage and anemia $(4,5)$.

Postpartum anemia is closely connected with the presence of anemia in pregnancy prior to delivery (prepartum anemia (10), which inevitably will be aggravated after delivery due to blood losses (2).

In the Western countries, the prevalence of prepartum anemia in the third trimester is markedly lower in women who have taken iron supplements during pregnancy compared with non-supplemented women. The major causes of postpartum anemia are prepartum iron deficiency/anemia in combination with excessive blood losses at delivery $(10,2)$.

In Europe, in selected series of healthy women after normal delivery, the prevalence of anemia (hemoglobin level $<11$ $\mathrm{g} / \mathrm{dL}$ ) 1 week postpartum is $14 \%$ in women who have taken iron supplements in pregnancy vs. $24 \%$ in non-supplemented women. In developing countries, the prevalence of postpartum anemia is considerably higher, in the range of $70 \%-80 \%$ (10). 
The post-partum period is defined as the period during which conditions return to the non-pregnant states (6).

Some studies have focused on iron administration to prevent anemia and the results obtained during pregnancy (7).

However, in Japan, it is conventionally reported that anemia will be alleviated by the 30th day post-partum recommends dietary therapy rather than prescribing iron tablets for p.o. administration when the hemoglobin level is between 9 and 11

$\mathrm{g} / \mathrm{dL}$ and mean corpuscular volume (MCV) is between 85 and $100 \mu \mathrm{m}^{3}$. If anemia is not alleviated by the 30th day postpartum, this will impede a full recovery from the delivery and will complicate child care, resulting in increases in fatigue (8).

\section{Aim of the work}

The aim of the study is to know the percentage of post-partum anemia and what are the risk factors for its development.

\section{Patients And Methods}

This study was a prospective cross section observational study, conducted at Obstetrics and Gynecology department, during the period (from September 2018 to March 2019).

- Population in patients around 6000 in one year delivered.

- Confidence interval (Cl):95\%.

- Power: $80 \%$.

- Frequency: $20 \%$.

- So sample size: 361 cases.

The Inclusion Criteria:-

All cases delivered at Zagazig University Hospital, during the period (from September 2018 to March 2019).

\section{The exclusion criteria:-}

1. Patient had medical or surgical disorder affecting hemoglobin level: including:fever , infection , diabetes mellitus , liver disease, renal disease, tuberculosis, cardiovascular disease, gastrointestinal symptoms/disease blood disease or cancer.

2. Per partum blood transfusion.

\section{Steps of performance:}

The study includes the patients who deliver (within two weeks after delivery).

\section{All patients were undergone the following}

Consent was taken from all patients

- Complete history taking, history of iron supplementation during pregnancy.

- History of antepartum hemorrhage.

- Complete clinical examination.

On admission and within two weeks after delivery, $3 \mathrm{ml}$ of blood was withdrawn by venipuncture into dry plastic tube containing Edeta solution. 
Hemoglobin (HB) concentration, hematocrit value (HCV), and other indices(mean corpuscular hemoglobin or $\mathrm{MCH}$, mean corpuscular hemoglobin concentration or $\mathrm{MCHC}$, and mean corpuscular volume or MCV) was determined in laboratory using automated counters.

Cases of PPA diagnosed at Level of hemoglobin concentration $<11 \mathrm{gm} / \mathrm{dl}$ Case with PPA was compared with cases without PPA as regarding

- HB before delivery.

- Antepartum hemorrhage.

- Estimated blood loss during labor.

Cases who need treatment were given oral or intravenous iron .,plus folic acid and vitamin B12 according to the type of anemia and cases with hemoglobin less than $6 \mathrm{gm} / \mathrm{dl}$ were given blood transfusion .

Follow up $\mathrm{CBC}$ was done 8 weeks after delivery

\section{STATISTICAL ANALYSIS}

All data were collected, tabulated and statistically analyzed using SPSS 20.0 for windows (SPSS Inc., Chicago, IL, USA) and MedCalc 13 for windows (MedCalc Software bvba, Ostend, Belgium). Quantitative data were expressed as the mean \pm SD \& median (range), and qualitative data were expressed as absolute frequencies (number) \& relative frequencies (percentage).

\section{Results}

Sample size 361 case the study showed postpartum anemia 236 case percentage of postpartum anemia is $65.4 \%$.

The study showed that percentage of antepartum anemia was about $64.3 \%$ this percentage postpartum increased to about $65.4 \%$ and $13.6 \%$ of those with antepartum normal hemoglobin level became anemic and there were $12.5 \%$ anemic improved postpartum and became normal.

\section{Types of postpartum anemia}

1. Mild normocytic normochromic anemia (HB 9.5-12 g/dl) (100 case).

2. Mild microcytic hypochromic anemia (68 cases).

3. Moderate normocytic normochromic anemia (HB 8-9.5 g/dl) (33 case).

4. Moderate microcytic hypochromic anemia (27 cases).

5. Severe normocytic normochromic anemia $(\mathrm{HB}<8 \mathrm{~g} / \mathrm{dl})$ (3 case).

6. Severe microcytic hypochromic anemia (5 cases).

The major causes of postpartum anemia are prepartum iron deficiency/anemia in combination with excessive blood losses at delivery.

Post-partum anemia is not affected by demographic data, obstetric history, ante-partum u/s and partum history .

Antepartum hemorrhage was not significantly associated with postpartum anemia. The more the estimated blood loss during labor the more the postpartum anemia .Through follow up of post-partum anemia cases and treated it according type of anemia(oral , intravenous, folate supplementation and blood transfusion ) Outcome of treatment of anemia after 8 weeks $61.02 \%$ is improved $\& 38.98 \%$ is not improved. 
Table (1): Prevalence of postpartum anemia in the studied pregnant women.

\begin{tabular}{|lll|}
\hline Postpartum anemia & \multicolumn{2}{l|}{ Total } \\
& $(\mathrm{N}=361)$ \\
\cline { 2 - 3 } & No. & $\%$ \\
\hline Absent & 125 & $34.6 \%$ \\
& & \\
\hline Present & 236 & $65.4 \%$ \\
\hline Mild normocytic normochromic & 100 & $42.37 \%$ \\
(HB 9.5-12 g/dl) & & \\
\hline Mild microcytic hypochromic & 68 & $28.81 \%$ \\
\hline Moderate normocytic & 33 & $13.98 \%$ \\
normochromic & & \\
(HB 8-9.5 g/dl) & & \\
\hline Moderate microcytic hypochromic & 27 & $11.44 \%$ \\
\hline $\begin{array}{l}\text { Severe normocytic normochromic } \\
\text { (HB <8 g/dl) }\end{array}$ & & $1.27 \%$ \\
\hline Severe microcytic hypochromic & 5 & $2.12 \%$ \\
\hline
\end{tabular}

Table (2): Prevalence of antepartum anemia in the studied pregnant women. 


\begin{tabular}{|lll|}
\hline Antepartum anemia & \multicolumn{2}{l|}{ Total } \\
& $(\mathrm{N}=361)$ \\
\cline { 2 - 3 } & No. & $\%$ \\
\hline Absent & 129 & $35.7 \%$ \\
\hline Present & & \\
\hline Mild normocytic normochromic & 232 & $64.3 \%$ \\
& & \\
\hline Mild microcytic hypochromic & & $45.26 \%$ \\
\hline Moderate normocytic normochromic & 20 & $8.62 \%$ \\
\hline Severe microcytic hypochromic & 5 & $2.16 \%$ \\
\hline Moderate microcytic hypochromic & 20 & $8.62 \%$ \\
\hline & & \\
\hline & & \\
\hline
\end{tabular}

Table (3): Relation between antepartum anemia, and postpartum anemia in the studied pregnant women.

\begin{tabular}{|c|c|c|c|c|}
\hline & & \multicolumn{2}{|c|}{ Postpartum anemia } & \multirow[t]{2}{*}{ Total } \\
\hline & & Absent & Present & \\
\hline \multirow[t]{4}{*}{ Antepartum anemia } & Absent & 80 & 49 & 129 \\
\hline & & $(22.2 \%)$ & $(13.6 \%)$ & $(35.7 \%)$ \\
\hline & Present & 45 & 187 & 232 \\
\hline & & $(12.5 \%)$ & $(51.8 \%)$ & $(64.3 \%)$ \\
\hline \multirow[t]{2}{*}{ Total } & & 125 & 236 & 361 \\
\hline & & $(34.6 \%)$ & $(65.4 \%)$ & $(100 \%)$ \\
\hline
\end{tabular}


Table (4): Relation between type of antepartum anemia, and postpartum anemia in the studied pregnant women.

\begin{tabular}{|c|c|c|c|c|c|c|c|c|c|}
\hline & & \multicolumn{7}{|c|}{ Postpartum anemia } & \multirow[t]{3}{*}{ Total } \\
\hline & & \multirow{2}{*}{$\begin{array}{l}\text { No } \\
\text { anemia }\end{array}$} & Mild & Mild & Mod. & Mod. & Sev. & Sev. & \\
\hline & & & NN & $\mathrm{MH}$ & NN & $\mathrm{MH}$ & NN & $\mathrm{MH}$ & \\
\hline \multirow{14}{*}{$\begin{array}{l}\text { Antepartum } \\
\text { anemia }\end{array}$} & No & 80 & 28 & 14 & 5 & 1 & 0 & 1 & 129 \\
\hline & Anemia & $(22.2 \%)$ & $(7.8 \%)$ & $(3.9 \%)$ & $(1.4 \%)$ & $(0.3 \%)$ & $(0 \%)$ & $(0.3 \%)$ & (35.7\%) \\
\hline & Mild & 23 & 54 & 9 & 9 & 7 & 1 & 2 & 105 \\
\hline & NN & $(6.4 \%)$ & $(15 \%)$ & $(2.5 \%)$ & $(2.5 \%)$ & $(1.9 \%)$ & $(0.3 \%)$ & $(0.6 \%)$ & $(45.26 \%)$ \\
\hline & Mild & 15 & 13 & 37 & 5 & 7 & 0 & 0 & 77 \\
\hline & $\mathrm{MH}$ & $(4.2 \%)$ & $(3.6 \%)$ & $(10.2 \%)$ & $(1.4 \%)$ & $(1.9 \%)$ & $(0 \%)$ & $(0 \%)$ & $(33.19 \%)$ \\
\hline & Mod. & 3 & 3 & 4 & 9 & 1 & 0 & 0 & 20 \\
\hline & NN & $(0.8 \%)$ & $(0.8 \%)$ & $(1.1 \%)$ & $(2.5 \%)$ & $(0.3 \%)$ & $(0 \%)$ & $(0 \%)$ & (8.62\%) \\
\hline & Mod. & 3 & 1 & 4 & 3 & 9 & 0 & 0 & 20 \\
\hline & $\mathrm{MH}$ & $(0.8 \%)$ & $(0.3 \%)$ & $(1.1 \%)$ & $(0.8 \%)$ & $(2.5 \%)$ & $(0 \%)$ & $(0 \%)$ & $(8.62 \%)$ \\
\hline & Sev. & 0 & 1 & 0 & 1 & 1 & 2 & 0 & 5 \\
\hline & NN & $(0 \%)$ & $(0.3 \%)$ & $(0 \%)$ & $(0.3 \%)$ & $(0.3 \%)$ & $(0.6 \%)$ & $(0 \%)$ & $(2.16 \%)$ \\
\hline & Sev. & 1 & 0 & 0 & 1 & 1 & 0 & 2 & 5 \\
\hline & $\mathrm{MH}$ & $(0.3 \%)$ & $(0 \%)$ & $(0 \%)$ & $(0.3 \%)$ & $(0.3 \%)$ & $(0 \%)$ & $(0.6 \%)$ & $(2.16 \%)$ \\
\hline \multirow[t]{2}{*}{ Total } & & 125 & 100 & 68 & 33 & 27 & 3 & 5 & 361 \\
\hline & & (34.6\%) & $(42.37 \%)$ & $(28.81 \%)$ & (13.98\%) & $(11.44 \%)$ & $(1.27 \%)$ & $(2.12 \%)$ & $(100 \%)$ \\
\hline
\end{tabular}

Table (5): Relation between demographic data, and postpartum anemia. 


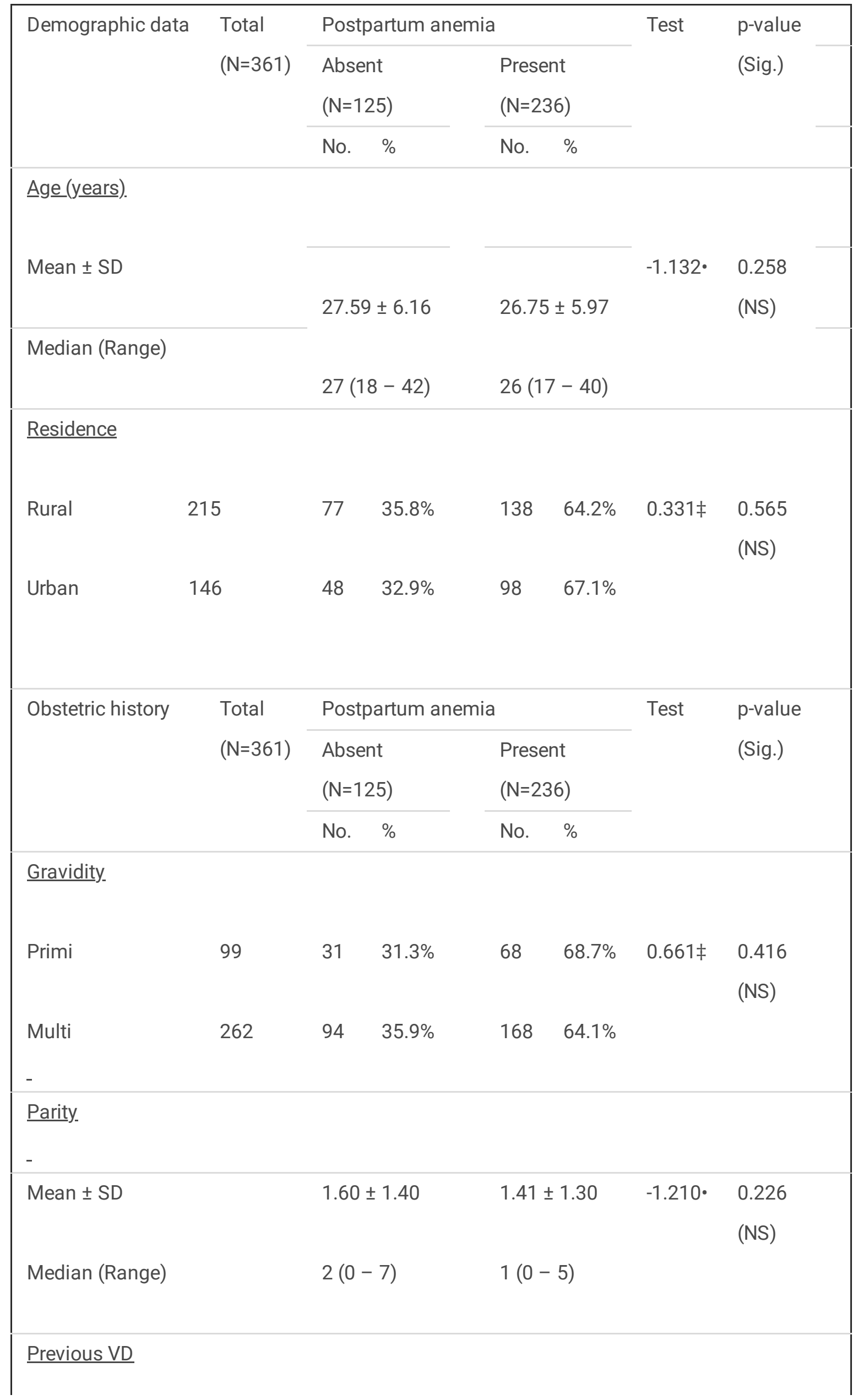




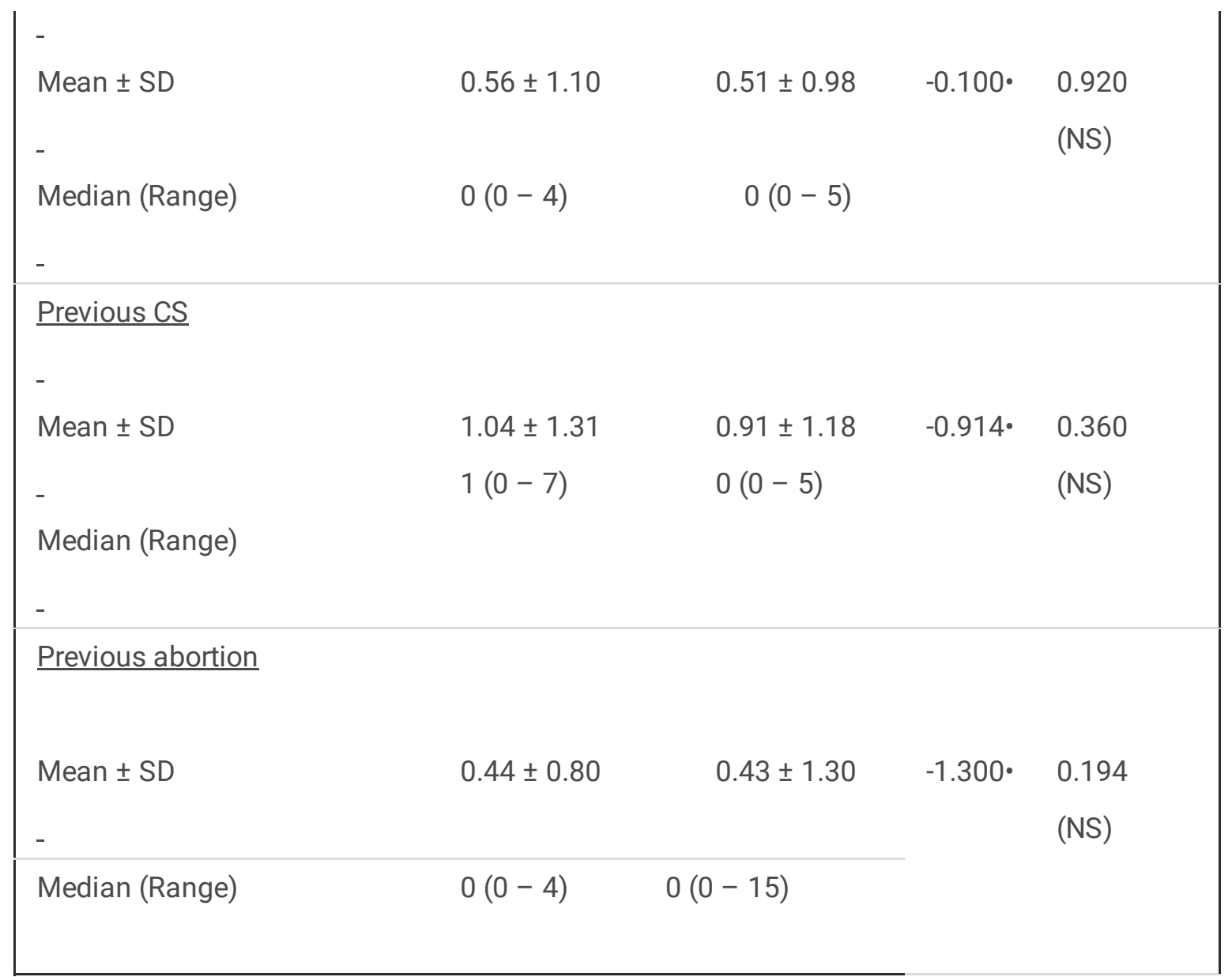

Table (6): Ante-partum RBCs indices in cases with or without postpartum anemia. 


\begin{tabular}{|c|c|c|c|c|}
\hline \multirow[t]{3}{*}{ Ante-partum RBCs indices } & \multicolumn{2}{|l|}{ Postpartum anemia } & \multirow[t]{3}{*}{ Test• } & \multirow{3}{*}{$\begin{array}{l}\text { p-value } \\
\text { (Sig.) }\end{array}$} \\
\hline & Absent & Present & & \\
\hline & $(N=125)$ & $(N=236)$ & & \\
\hline \multicolumn{5}{|l|}{$\underline{\text { RBCs count }}\left(\underline{x 10}^{6} / \mathrm{mm}^{3}\right)$. } \\
\hline \multirow{2}{*}{ Mean \pm SD } & $4.34 \pm 0.51$ & $3.88 \pm 0.56$ & -7.050 & \\
\hline & & & & $(\mathrm{HS})$ \\
\hline Median (Range) & $4.30(3.20-6.50)$ & $4(1.80-5.20)$ & & \\
\hline \multicolumn{5}{|l|}{ Hematocrit (\%). } \\
\hline Mean \pm SD & $35.98 \pm 3.03$ & $30.85 \pm 3.86$ & -11.420 & $<0.001$ \\
\hline- & & & & $(\mathrm{HS})$ \\
\hline Median (Range) & $35.50(29.80-47.50)$ & $30.95(15.50-41.10)$ & & \\
\hline \multicolumn{5}{|l|}{ Hemoglobin $(\mathrm{g} / \mathrm{dl})$. } \\
\hline Mean \pm SD & $12.39 \pm 0.91$ & $10.45 \pm 1.25$ & -12.840 & $<0.001$ \\
\hline- & & & & $(\mathrm{HS})$ \\
\hline Median (Range) & $12.40(10.30-15.50)$ & $10.60(5.40-11)$ & & \\
\hline \multicolumn{5}{|l|}{ MCV } \\
\hline Mean \pm SD & $83.32 \pm 6.30$ & $79.58 \pm 7.71$ & -4.348 & $<0.001$ \\
\hline- & & & & $(\mathrm{HS})$ \\
\hline Median (Range) & $84(63-100)$ & $80.70(56-96)$ & & \\
\hline \multicolumn{5}{|l|}{$\underline{\mathrm{MCH}}$} \\
\hline Mean \pm SD & $28.10 \pm 2.51$ & $26.45 \pm 3.20$ & -4.907 & $<0.001$ \\
\hline- & & & & $(\mathrm{HS})$ \\
\hline Median (Range) & $28.10(20.10-34.10)$ & $27(18.40-34.60)$ & & \\
\hline \multicolumn{5}{|l|}{$\underline{\mathrm{MCHC}}$} \\
\hline \multirow[t]{2}{*}{ Mean \pm SD } & $33.50 \pm 1.54$ & $33.14 \pm 1.81$ & -2.018 & $<0.001$ \\
\hline & & & & $(\mathrm{HS})$ \\
\hline Median (Range) & $34(27.50-36.30)$ & $33.40(28-37.60)$ & & \\
\hline \multicolumn{5}{|l|}{$\underline{\mathrm{RWD}}$} \\
\hline \multirow[t]{2}{*}{ Mean \pm SD } & $14.42 \pm 1.80$ & $15.16 \pm 2.68$ & -2.807 & $<0.001$ \\
\hline & & & & $(\mathrm{HS})$ \\
\hline Median (Range) & $14(11.30-21)$ & $14.50(3.10-26.90)$ & & \\
\hline
\end{tabular}


Table (7): Relation between ante-partum hemorrhage, and postpartum anemia.

\begin{tabular}{|c|c|c|c|c|c|c|c|}
\hline \multirow[t]{4}{*}{ Ante-partum hemorrage } & \multirow{4}{*}{$\begin{array}{l}\text { Total } \\
(\mathrm{N}=36)\end{array}$} & \multicolumn{4}{|c|}{ Postpartum anemia } & \multirow[t]{4}{*}{ Test } & \multirow{4}{*}{$\begin{array}{l}\text { p-value } \\
\text { (Sig.) }\end{array}$} \\
\hline & & \multirow{2}{*}{\multicolumn{2}{|c|}{$\begin{array}{l}\text { Absent } \\
(\mathrm{N}=125)\end{array}$}} & \multirow{2}{*}{\multicolumn{2}{|c|}{$\begin{array}{l}\text { Present } \\
(\mathrm{N}=236)\end{array}$}} & & \\
\hline & & & & & & & \\
\hline & & No. & $\%$ & No. & $\%$ & & \\
\hline \multicolumn{8}{|l|}{$\underline{\mathrm{APH}}$} \\
\hline Absent & 293 & 105 & $35.8 \%$ & 188 & $64.2 \%$ & 1.006 & 0.316 \\
\hline Present & 68 & 20 & $29.4 \%$ & 48 & $70.6 \%$ & & (NS) \\
\hline \multirow[t]{5}{*}{ Estimated blood loss during labour } & Total & \multirow{2}{*}{\multicolumn{4}{|c|}{ Postpartum anemia }} & Test & $\mathrm{p}$-value \\
\hline & $(\mathrm{N}=36)$ & & & & & & (Sig.) \\
\hline & & \multirow{2}{*}{\multicolumn{2}{|c|}{$\begin{array}{l}\text { Absent } \\
(\mathrm{N}=125)\end{array}$}} & \multirow{2}{*}{\multicolumn{2}{|c|}{$\begin{array}{l}\text { Present } \\
(\mathrm{N}=236)\end{array}$}} & & \\
\hline & & & & & & & \\
\hline & & No. & $\%$ & No. & $\%$ & & \\
\hline $200-300$ cc (VD) & 56 & 23 & $41.1 \%$ & 33 & $58.9 \%$ & 10.622 & 0.014 \\
\hline$>300$ cc (VD) & 35 & 8 & $22.9 \%$ & 27 & $77.1 \%$ & & (S) \\
\hline $500-1000$ cc (CS) & 184 & 74 & $40.2 \%$ & 110 & $59.8 \%$ & & \\
\hline >1000 cc (CS) & 86 & 20 & $23.3 \%$ & 66 & $76.7 \%$ & & \\
\hline
\end{tabular}

Table (8): Treatment of postpartum anemia, and its outcome in the studied women.

\begin{tabular}{|lll|}
\hline Treatment of postpartum anemia & \multicolumn{2}{l|}{ Total } \\
& $(\mathrm{N}=236)$ \\
\cline { 2 - 3 } & No. $\%$ \\
\hline Treated & 236 & \\
Treated by oral iron & 168 & $71.18 \%$ \\
Treated by IV iron & 60 & $25.42 \%$ \\
Treated by blood transfusion & 8 & $3.38 \%$ \\
\hline Outcome of treatment of postpartum anemia & Total \\
& $(\mathrm{N}=236)$ \\
\cline { 2 - 3 } & No. & $\%$ \\
Treated & 236 & \\
Improved & 144 & 61.02 \\
Not improved & 92 & 38.98 \\
\hline
\end{tabular}




\section{Discussion}

Iron deficiency anemia (IDA) in pregnancy, i.e., prepartum anemia, is associated with premature birth, low birth weight, and small for gestational age of the newborn and is furthermore closely associated with the occurrence of anemia after delivery of achild, i.e., in the postpartum period (1).

Postpartum iron deficiency and anemia are associated with an impaired quality of life from a physical and a psychological point of view and constitutes a significant health problem both in developed and developing countries (9)

the study showed percentage of postpartum anemia is $64.3 \%$, absence of postpartum anemia is $35.7 \%$ \& showed that postpartum anemia is not affected by demographic data( age ,residence)

In Europe, in selected series of healthy women after normal delivery, the prevalence of anemia (hemoglobin level $<11$ $\mathrm{g} / \mathrm{dL}$ ) 1 week postpartum is $14 \%$ in women who have taken iron supplements in pregnancy vs. $24 \%$ in non-supplemented women(10). In unselected series of women who have not taken iron supplements, the prevalence of anemia (hemoglobin level $<11 \mathrm{~g} / \mathrm{dL}) 48 \mathrm{~h}$ after delivery is approximately $50 \%(2)$.

Postpartum anemia is closely connected with the presence of anemia in pregnancy prior to delivery (prepartum anemia which inevitably will be aggravated after delivery due to blood losses (2).

\section{The study showed percentage of types of postpartum anemia}

Mild normocytic normochromic anemia $42.37 \%$ \& Mild microcytic hypochromic anemia $28.81 \% \&$ Moderate normocytic normochromic $13.98 \% \&$ Moderate microcytic hypochromic $11.44 \% \&$ Severe normocytic normochromic $1.27 \% \&$ severe microcytic hypochromic $2.12 \%$.

The study showed that cases with postpartum anemia had a mean antepartum HB at $10.45 \mathrm{~g} / \mathrm{dl}$ and cases without postpartum anemia had a mean antepartum HB at 12.39 and cases with antepartum anemia was significantly associated with postpartum anemia \& percentage of antepartum anemia was about $64.3 \%$ this percentage postpartum increased to about $65.4 \%$ and $13.6 \%$ of those with antepartum normal hemoglobin level became anemic and there were $12.5 \%$ anemic improved postpartum and became normal

In a Danish series in 1991 of iron-supplemented women after a normal singleton pregnancy and delivery (11), the mean hemoglobin concentration 1 week postpartum was $12.7 \mathrm{~g} / \mathrm{dL}$ (95\% Cl 10.2-14.7), whereas non-supplemented women had a mean hemoglobin of $11.8 \mathrm{~g} / \mathrm{dL}(95 \% \mathrm{Cl} 9.7-13.9)$

\section{The study showed percentage of types of antepartum anemia}

mild normocytic normochromic $45.26 \%$ \& mild microcytic hypochromic $33.19 \%$ \& moderate normocytic normochromic $8.62 \%$ \& moderate microcytic hypochromic $8.62 \%$ \& severe normocytic normochromic $2.16 \%$ \& severe microcytic hypochromic $2.16 \%$.

Studies on healthy Scandinavian pregnant women without iron deficiency, singleton pregnancy, and living at sea level $(11,12,13,14)$ have shown that in late third trimester, the fifth percentile for the hemoglobin concentration is $11-11.1 \mathrm{~g} / \mathrm{dL}$ and the lower reference value of the $95 \%$ confidence interval $(\mathrm{Cl})$, corresponding to the 2.5 th percentile, is $10.8 \mathrm{~g} / \mathrm{dL}$.

The study showed that antepartum hemorrhage was not significantly associated with post-partum anemia

The study showed that the more the estimated blood loss during labor the more the postpartum anemia. 
In a Dutch study (15) comprising 367 women with vaginal deliveries and a low risk of postpartum hemorrhage ,blood losses within $1 \mathrm{~h}$ of delivery of placenta were measured by a gravimetric method.

Median (5-95 percentile) blood losses were $375 \mathrm{ml}(125-1,500)$; losses were $\geq 500 \mathrm{ml}$ in $38 \%$ and $\geq 1,000 \mathrm{ml}$ in $10 \%$ of the women, which are higher than in studies using subjective estimates of blood losses (16).

In New South Wales blood losses $>500 \mathrm{ml}$ were observed in $13.1 \%$ of deliveries. Among deliveries in Norway in 19992004 , severe obstetric hemorrhage $>1,500 \mathrm{ml}$ within $24 \mathrm{~h}$ postpartum occurred in $1.1 \%$ (17).

Postpartum hemorrhage occurs in 4-6\% of all deliveries (18) but there are considerable discrepancies between blood losses estimated by midwifes/obstetricians and true blood losses.

In Denmark in 2002-2005, postpartum hemorrhage (estimated blood losses $>500 \mathrm{ml}$ ) occurred in $5.1 \%$ of primiparous women corresponding to 3,500 deliveries per year (19).

This study showed that $71.18 \%$ treated by oral iron, $25.42 \%$ treated by IV iron, $3.38 \%$ treated by blood transfusion \& outcome of treatment of anemia after 8 weeks $61.02 \%$ is improved $\& 38.98 \%$ is not improved.

In women taking $66 \mathrm{mg}$ ferrous iron/day during pregnancy, anemia (hemoglobin level $<11 \mathrm{~g} / \mathrm{dL}$ ) at 1 week postpartum was observed in $14 \%$ vs. in $22 \%$ of women taking placebo tablets $(20,11)$. Eight weeks postpartum, anemia (hemoglobin level $<12.1 \mathrm{~g} / \mathrm{dL}$ ) was observed in $6 \%-8 \%$ of women who had been taking iron vs. $16 \%$ in women taking placebo $(\mathbf{1 1}, \mathbf{2 0}$, 21). Oral iron therapy should be the first therapeutic option in women having slight-to-moderate IDA with hemoglobin levels of $9.5-12 \mathrm{~g} / \mathrm{dL}$.

They should initially be treated with ferrous iron 100-200 mg/day (22).

Such high doses of iron should preferably be administered between meals as a sustained release iron preparation in order to optimize absorption and reduce gastrointestinal side effects (23). Following treatment for 2 weeks, the therapeutic response should be checked by measurement of hemoglobin. In order to keep the solution stable, iron sucrose should be dissolved in a maximum of $200 \mathrm{ml}$ isotonic saline, infused over a minimum of $30 \mathrm{~min}$; repetitive doses should be administered with a minimum of 3-days interval (22). At profound anemia with hemoglobin level of $<6 \mathrm{~g} / \mathrm{dl}$, blood transfusion should be considered (23).

\section{Conclusion}

The major causes of postpartum anemia are pre-partum iron deficiency/anemia in combination with excessive blood losses at delivery.

The study showed that percentage of antepartum anemia was about $64.3 \%$ this percentage postpartum increased to about $65.4 \%$ and $13.6 \%$ of those with normal antepartum hemoglobin level became anemic postpartum and there were $12.5 \%$ anemic improved postpartum and became normal.

\section{References}

1 Milman N (2008) Pre partum anemia: prevention and treatment. Ann Hematol 87:949-959.

2 Bergmann RL, Richter R, Bergmann KE, Dudenhausen JW (2010) Prevalence and risk factors for early postpartum anemia. Eur J Obstet Gynecol Reprod Biol 150:126-131. 
3 Bodnar LM, Siega-Riz AM, Miller WC, Cogswell ME , McDonald T (2002) Who should be screened for postpartum anemia? An evaluation of current recommendations. Am J Epidemiol 156:903 912.

4 World Health Organization (1999) Reduction of maternal mortality. A joint WHO/UNFPA/UNICEF/World Bank statement. World Health Organization, Geneva.

www.altomkost.dk Accessed January (2010).

www.meraadet.dk Accessed March( 2008).

5 Potts M and Campbell M (2004) Three meetings and fewer funerals: misoprostol in postpartum hemorrhage. Lancet 364:1110-1111.

6 Mori and E. (2012). Study skill ii, maternity nursing 2, systematic nursing science, 12 (p. 525). Tokyo: Igaku-Shoin, Ltd. (in Japanese).

7 Abdullahi, H., I., Saeed, A., Imam, A.M. \& Adam, I. (2014). Antenatal iron and folic acid supplementation use by pregnant women in Khartoum, Sudan. BMC Research Notes, 7, 498. misoprostol in postpartum hemorrhage. Lancet 364:11101111.

8 Saotome, T. , Murakami, et al., (2006). Recovering to make child-rearing comfortable - Support for recovery from anemia for postpartum mothers. Perinatal Care, 25, 228-229.

9 Protonotariou E, Chrelias C, Kassanos D, Kapsambeli H, Trakakis E, Sarandakou A (2010) Immune response parameters during labor and early neonatal life. In Vivo 24:117-123.

10 Milman N.(2011) Anemia-still a major health problem in many parts of the world! Ann Hematol 2011; 90:369-377. http://dx.doi.org/ 10.1007/s00277-010-1144-5.

11 Milman N, Agger OA, Nielsen OJ (1991) Iron supplementation during pregnancy. Effect on iron status markers, serum erythropoietin and human placental lactogen. A placebo controlled study in 207 Danish women. Dan Med Bull 38:471476.

12 Milman N, Byg K-E, Graudal N, Agger AO (2000) Reference values for hemoglobin and erythrocyte indices during normal pregnancy in 206 women with and without iron supplementation. Acta Obstet Gynecol Scand 78:89-98.

13 Milman N, Bergholdt T, Byg K-E, Eriksen L, Hvas A-M (2007) Reference intervals for haematological variables during normal pregnancy and postpartum in 433 healthy Danish women. Eur J Haematol 79:39-46.

14 Milman N, Ibsen KK, Christensen JM (1987) Serum ferritin and iron status in mothers and newborn infants. Acta Obstet Gynecol Scand 66:205-211.

15 Groot AN, van Roosmalen J, van Dongen PW, Borm GF (1996) A placebo-controlled trial of oral ergometrine to reduce postpartum hemorrhage. ActaObstetGynecolScand 75:464-468.

16 Gilbert L, Porter W, Brown VA (1987) Postpartum haemorrhage a continuing problem. British Journal of Obstetrics and Gynaecology 94:67-671.

17 Al-Zirqi I, Vangen S, Forsen L, Stray-Pedersen B (2008) Prevalence and risk factors of severe obstetric hemorrhage. BJOG 115:1265 
18 Oyelese Y and Ananth CV (2010) Postpartum hemorrhage: epidemiology, risk factors, and causes. Clin Obstet Gynecol 53:147-15654) Expertenbrief 2007 no. 22.

19 Danish Society for Obstetrics and Gynaecology http://www.dsog.dk. (2011).

20 Milman N (2011) Postpartum anemia I: definition, prevalence, causes and consequences. Ann Hematol 90:12471253.

21 Milman N, Bergholt T, Eriksen L, Byg K-E, Graudal N, Pedersen P, Hertz J (2005) Iron prophylaxis during pregnancyhow much iron is needed? A randomised, controlled study of 20 to $80 \mathrm{mg}$ ferrous iron daily to pregnant women. ActaObstetGynecolScand 84:238-247.

22 Breymann C, Honegger C, Holzgreve W, Surbek D (2007) Diagnostik und Therapie der Anämie in der Schwangerschaft und postpartal. Schweizerische Gesellschaft für Gynäkologie und Geburtshilfe (Quated from Milman (2012) Ann Hematol 91:143-151

23 Nielsen JB, Ikkala E, Sölvell L, Björn-Rasmussen E, Ekenved G (1976) Absorption of iron from slow-release and rapidly disintegrating tablets-a comparative study in normal subjects, blood donors and subjects with iron deficiency anemia. Scand J Haematol Suppl 28:89-97.

24 Beris P, Maniatis A, on behalf of the NATA working group on intravenous iron therapy(2007). Guidelines on intravenous iron supplementation in surgery and obstetrics/gynecology. Transfusion Alternatives in Transfusion Medicine2007;9 Suppl 1:29.

\section{Declarations}

\section{- Conflict of interest}

The authors of this manuscript declare no relevant conflicts of interest, and no relationships with any companies, whose products or services may be related to the subject matter of the article.

- Funding

The authors state that this work has not received any funding.

- Ethical approval

Institutional review boards approval was obtained.

- Informed consent

Written informed consent (Consent to Participate and Consent to Publish) was obtained from all patients.

- Statistics and biometry

The corresponding author has great statistical expertise

- Author contribution:

- Safaa A. Ibrahim: (First author)

- Abstract.

- Methodology

- Results. 
- Mena M. Abdalla: (Second \& corresponding author)

- collecting data

- literature of review

- Statistical analysis and discussion.

- Rofida M. Elshafei:

- introduction \& references. 